\title{
How to Teach CAD/CAE Systems
}

\author{
https://doi.org/10.3991/ijep.v8i1.8185 \\ Peter Kuna, Alena Hašková( $\left.{ }^{\bowtie}\right)$, Miloš Palaj, Miloslav Skačan \\ Constantine the Philosopher University, Nitra, Slovak Republic \\ ahaskova@ukf.sk \\ Ján Záhorec \\ Comenius University, Bratislava, Slovak Republic
}

\begin{abstract}
In the traditional methodology of CAD system teaching, one starts with the acquisition of technical drawing principles and design of technical schemes and drawings based on manual drawing. Only subsequently do students learn to draw schemes and technical drawings using one of the CAD systems. An alternative possibility in teaching CAD/CAE could be to start immediately with machine element draughts and modelling and to pay only marginal attention to the teaching of technical drawing, in a reduced time frame. A key question related to the authors' proposed method of teaching CAD/CAE is whether a reduction in technical drawing teaching will have a negative impact on student attainment. An answer to this question shall be derived from a pedagogical experiment which the authors intend to carry out, the methodology of which is presented in the paper.
\end{abstract}

Keywords - CAD/CAE systems, innovative methods of teaching, upper secondary education (ISCED 3 )

\section{Background}

Computer aided systems are systems dedicated foremost to supporting activities in the area of graphical output projection and creation [1]. They are perhaps most often utilized in the engineering industry, where they are used in every production phase from machine part design, through production planning, assembly, storage and transportation [2]. Nowadays they are also used in various other industry sectors as well as at different management levels. They enable the performance of different engineering activities such as drawing, constructing, dimensioning and projecting, but also many administrative activities such as archiving, searching, reproduction, etc. - more quickly and more easily.

Right from the start, it is important to define and explain which computer aided systems are defined as CAD, i.e. Computer Aided Design (Drawing) systems, and which are defined as CAE, i.e. Computer Aided Engineering systems. CAD systems are defined as those that mostly support the field of drawing and the creation of technical documentation, and CAE systems are those which support 3D modelling and 
simu-lations in the computer environment of virtual reality. CAD/CAE refers to CAD and CAE systems together, i.e. it refers to the meaning "everything together" [3].

The role of the CAD system is to aid the designer by providing him/her the possibi-lity to:

- create and modify a graphical representation of the product,

- view the actual product on screen,

- make any modifications to the graphical representation of the product,

- present ideas on screen without a prototype, especially during the early stages of the design process,

- perform complex design analysis in a short time,

- store the whole design and processing history of a certain product, for future reuse and upgrade [4].

Nowadays we cannot imagine the effective design of new products without the use of $\mathrm{CAD} / \mathrm{CAE}$ systems. These systems are not only intrinsic to the pre-manufacturing phase of production, but also add the option of modification of existing products. They are approaching the world of virtual reality, in which engineers and designers have the option to apply their creativity and inventiveness. CA technologies enable the recreation of the geometry of models, the design of further technological parameters and enable even the design of the production process. The defined models can be in a very simple way adjusted, modified and also their mechanical properties can be very easily derived. The advantage of computer created design is its close continuity to the next technological activity. The geometries of objects created in this way can be used for example as material for the programming of machine tools. A separate process is the linking of the created objects to larger assemblies and computer simulations. CA technologies enable the testing and proof of functionality of a designer's ideas before their product becomes an object in the real world. This substantially expands the possibilities of the design and the effective creation of a larger amount of ideas and modifications, which otherwise would be financially very demanding [5].

The economic and technical aspects of the use of CA systems in design and manufacturing are generally known. In the last decade, we have witnessed the diminishing role of CA systems simply as support tools for creating technical documentation. Current trends in their use emphasize the importance of human creativity. For example, CA systems today have very elegant and efficient tools for the automated creation of technical documentation, so the designer is not burdened by the lengthy and routine creation of technical drawings. Today the trend in technical communication is the preference of virtual 3D models rather than drawing documentation. In any case, CA systems are trying to relieve creators of routine and time-consuming tasks. High emphasis is placed on the inventiveness and creativity of the human mind, which we cannot replace with computer algorithmization.

In recent years, the Slovak Republic has become a European power in car manufacturing. Availability and quality of skilled labor is one of the most significant problems for suppliers and manufacturers in the automotive industry, as there is a high demand for skilled workers from technical professions [6]. The education system should reflect the needs and interests of industry, and knowledge and skills in CA 
technologies have become one of the key requirements for the successful entry of graduates of technical schools into the workplace.

\section{Practical aspects of work in CAD/CAE system environments}

CAD systems are software products that support a broad range of activities associated with machine design, tool design and technical element design. This creative process starts with the creation of the very first model draught and continues with the elabo-ration of technical documentation and processing of technical drawings. Due to these, it is possible to prepare technical documentation containing all necessary dimensions and parameters (size) of each of the elements of the created product. For many years, CAD systems have offered a modern method to design new products and elements, to design their geometry and to elaborate corresponding technical drawings. In a way they replace the drawing board and provide their users a new dimension in technical drawing. Last but not least, these software products also offer the possibility for subsequent editing of already created components. Programs of this type are based on the principles of the interaction of computer graphics, and that is why they find a broad application mainly in the car and machine industry.

In general, technical drawing can be divided into two basic types. The first type is based on the standard (traditional) drawing of technical plans. It is the standard environment for $2 \mathrm{D}$ modelling. The other type is based on a new method of technical component parts design - so-called parametric modelling. Thanks to its contributions, this type of modelling has revolutionized industry.

There are different types of CAD systems on the market. In relation to upper secon-dary technical schools in Slovakia (ISCED 3), in order to fulfil their practical demands one of the most often used CAD systems is the Autodesk CAD suite, which contains a whole range of software products such as CAD, Autodesk Inventor Professional and Fusion. To design technical components parts and to prepare the relevant technical do-cumentation it is very important to have at one's disposal, in addition to the software, the appropriate hardware resources, as CAD systems need powerful graphic support for efficient and smooth running.

Familiarization of secondary school students (ISCED 3) with work in a CAD/CAE system environment begins with their familiarization with the software. After that, students start to learn to create the first lines and simple draughts of $2 \mathrm{D}$ components. For this they use software tools such as abscissa, curved lines, circle, arch etc. (Fig. 1).

A very important feature of CAD/CAE systems is the command line. Through this line students learn to design technical elements by means of precisely given commands. The command line offers either options on how to use the particular tool or the next steps to complete the design process. It helps to determine particular parameters (sizes) of the relevant parts of the designed model, or a menu of the other functions which can or must be chosen (e.g. for a circle it is necessary to give the value of Radius, Fig. 2). 


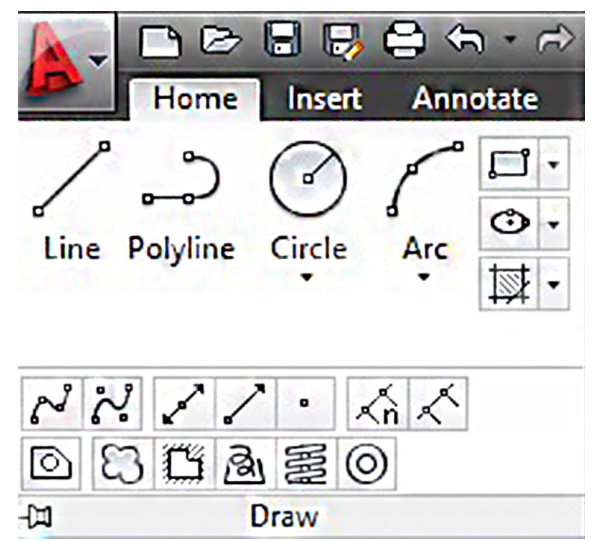

Fig. 1. Basic tools for $2 \mathrm{D}$ component parts design

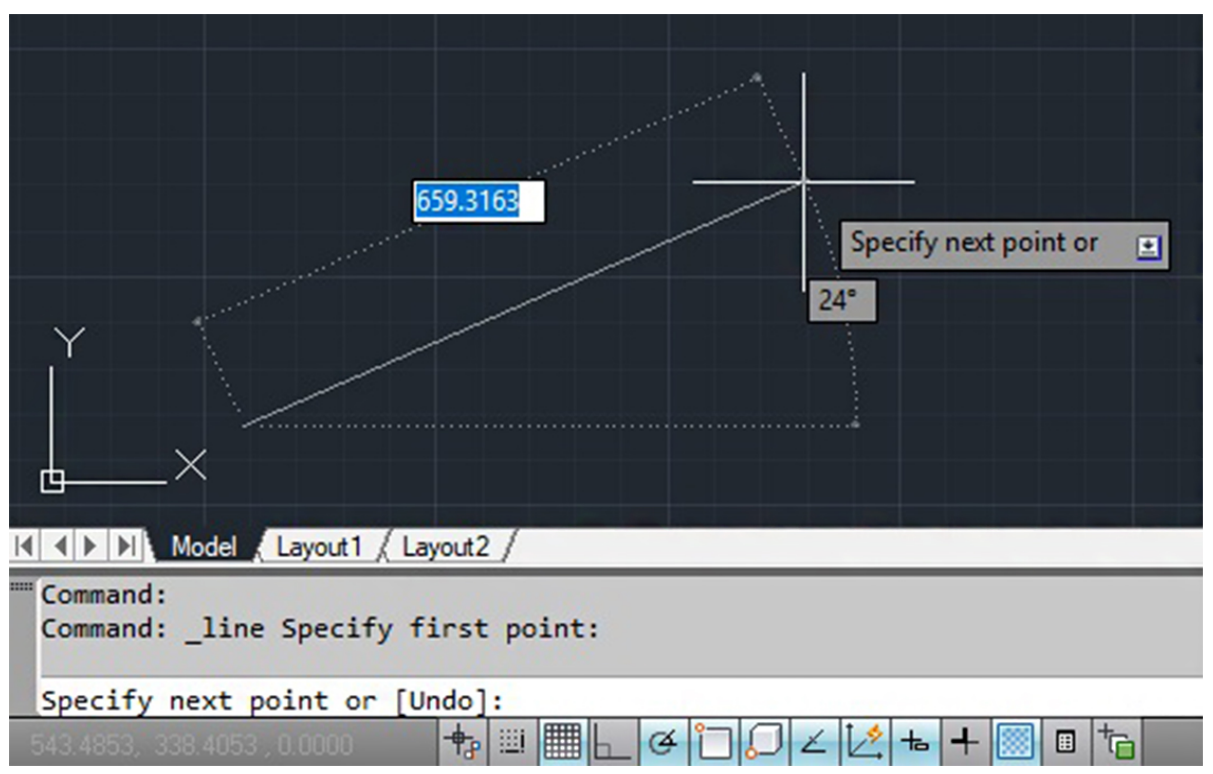

Fig. 2. Tools to design technical elements

The next step is to learn to dimension particular parts of the designed technical element (Fig. 3). From the point of view of the technical drawings' further use, this is the most important step in the whole process.

In a CAD system environment there is a possibility to shift the draught creation to the level of so-called parametric modelling. As Fig. 4 shows, after the completion of the technical element design the program can be switched over to 3D modelling. Consequently the program offers various possibilities (tools) for parametric modelling development. By means of these parametric modelling tools students learn to add into the designed draught such details as different fillets, twists, holes, slopes and different textures (Fig. 4). 


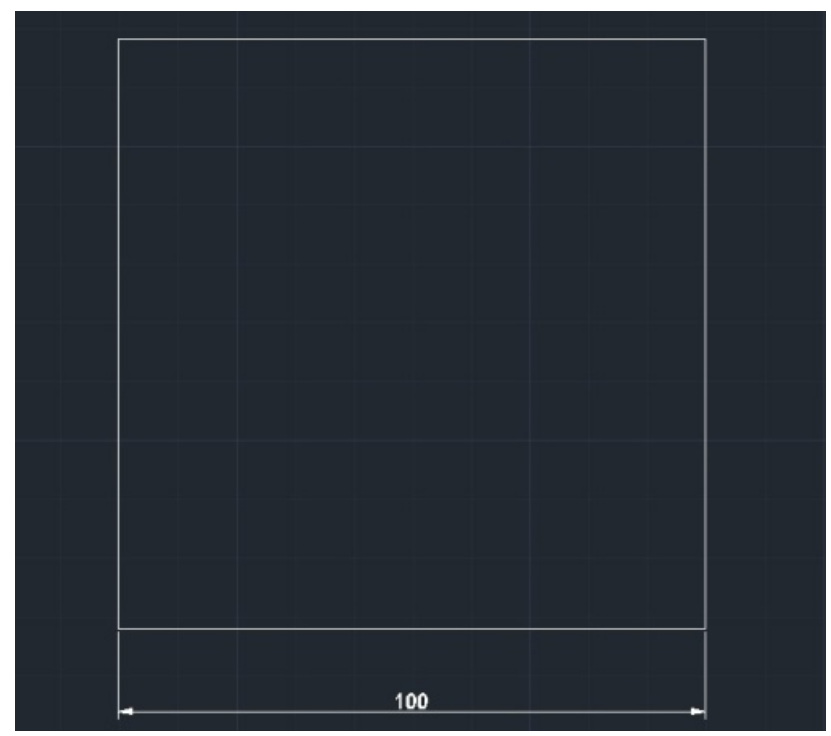

Fig. 3. A CAD draught

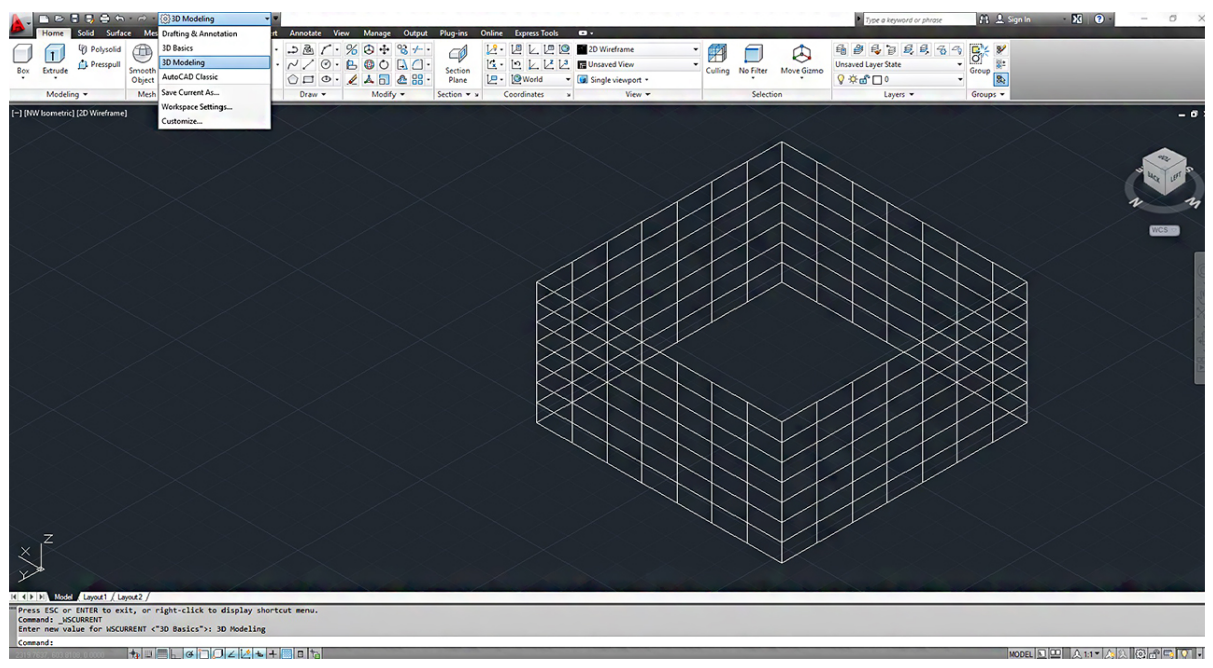

Fig. 4. Example of a technical element draught

In the case of parametric modelling the operation process is opposite to the one used in the case of traditional 2D modelling. This means that students from the beginning create models without any previous experience nor knowledge of the rules of traditional drawing in CAD software products. The most expanded program of the different ones available on the market is Inventor from the firm Autodesk [2]. Students already in the first lessons learn to design different elements and their parameters (size, thickness, fillet, etc.). A very important first step after program start-up is selection of the right technical norm under which students will create the given tech- 
nical element (Fig. 5). Working with our national norms, parameters in millimetres $(\mathrm{mm})$ are used.

The environment of the parametric modelling is almost identical to the CAD environment, but it involves some additional functions and mainly the window Model (Fig. 6), due to which students can manage the layers and can also switch among the draughts and their attributes.

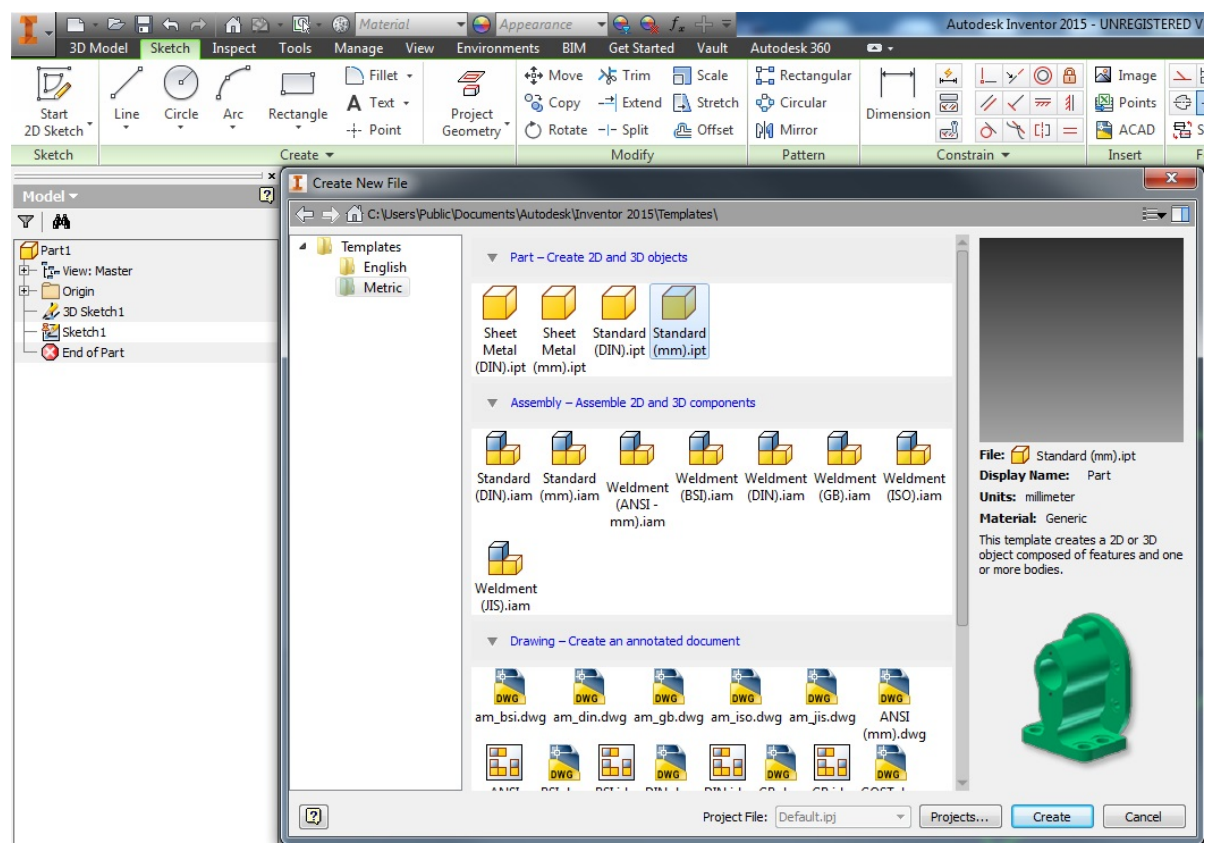

Fig. 5. Norm selection

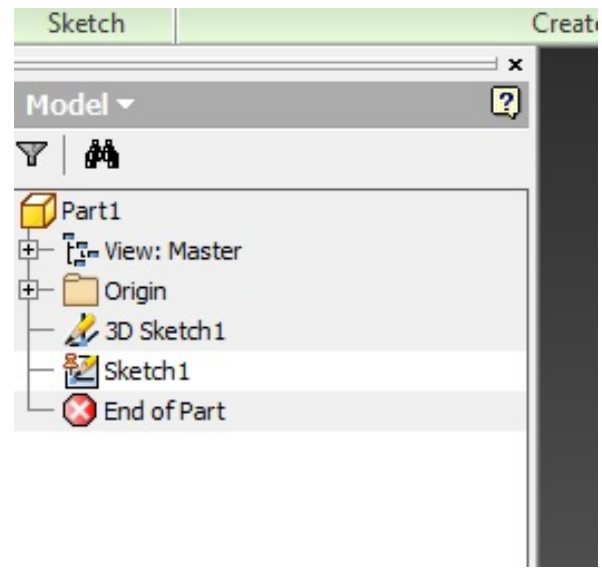

Fig. 6. Norm selection 
Another difference is the addition of the button Finish Sketch (Fig. 7). After completion of the draught the program leads the user into a 3D design, where the students can make further modifications in the designed component part.

After draught completion students can switch into 3D space, where they have at their disposal further tools necessary for 3D modelling (Fig. 8). Consequently they work with the designed technical component part, modify its attributes, add twists, holes and other features, according to stated needs.

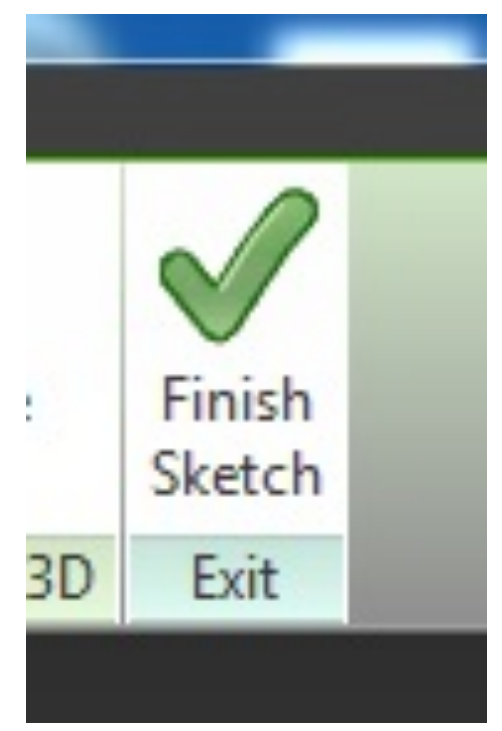

Fig. 7. Tool for a draught completion

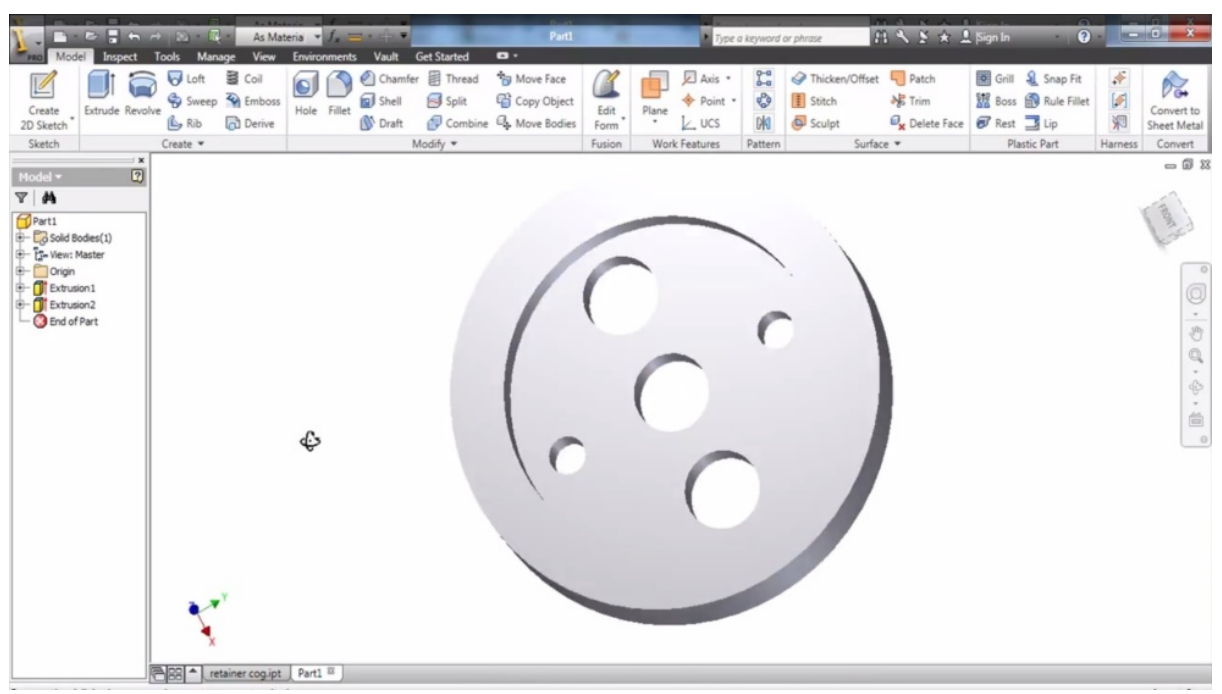

Fig. 8. Example of a 3D model 


\section{How to teach CAD/CAE systems: statement of the research question}

Computer aided design (drawing) has been a part of study program curricula from secondary schools to university level for a long time ([7], [8], [9]). Due to the constantly increasing importance of CAD education more and more attention is being paid to the question of how to teach CAD in practice ([10], [11], [12], [13]). Consequently the answer to this question, i.e. the general concepts, curricula for different stages of CAD knowledge, new teaching methods and didactical principles and new roles of teachers, has to be reflected also in relevant teacher training programs ([14], [15], [16]). Teaching CAD is a very complex topic. A good teacher should understand the difficulties of learning CAD and should be able to counteract these problems in various ways. Teaching CAD systems should provide students with a wide diversity of problems and tasks and in this way by problem- and process-oriented sequences, the teacher should promote students' autonomous learning [10]. When a teacher starts to acquaint the students with work with CAD systems, it is important to ensure that the students do not develop a dislike for these systems, or a feeling that their study is too difficult and complicated. A student must be offered education so that $\mathrm{s} / \mathrm{he}$ enjoys the journey of acquiring new knowledge and skills, while picking up the principles of the field naturally [8].

The traditional methodology of CAD system teaching arises from the historical technical development of the field of CAD systems. The first phase is acquisition of technical drawing principles. Students design schemes or technical drawings based on manual drawing. Only during the next phase are computers substituted for the drawing board and the students learn to draw schemes and technical drawings in one of the CAD systems. In this case the process of education is focused on acquisition of practice (technique) at work with the software assigned for technical documentation creation, including technical drawings. The third stage is focused on computer assisted design of technical layouts and constructions. Students design machine elements by means of $\mathrm{CAD} / \mathrm{CAE}$ systems and compose them into integrated technical constructions.

Today's CAD-CAE systems are able to generate automatically complex technical documentation following the design and simulation test phase of the components or of the functional units. Through a survey of labor market requirements, we have found that the emphasis of graduate requirements is precisely on the field of modelling and simulation. At present, in technical practice, inventor's creativity and inventiveness is more valuable than precise knowledge of rules and standards for the production of technical documentation. Of course, we do not want to claim that accurate and standardized drawing of technical drawings is not a necessary part of the work of technical workers. However, current developments and trends in the use of CAD/CAE systems unambiguously point to a retreating trend in these skills, in favor of the creativity and invention of the designer. In the final phase, the designer can generate accurate technical documentation through a computer within several seconds. 


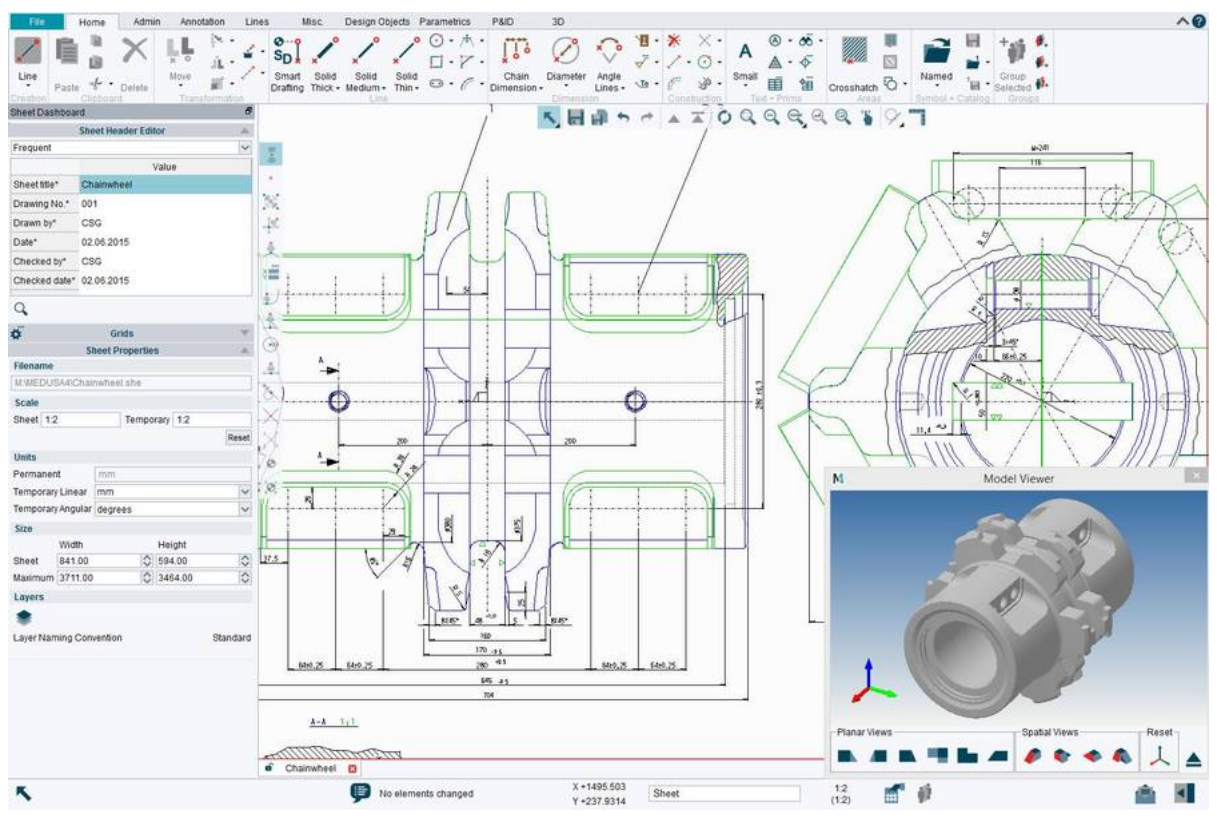

Fig. 9. Example of a 3D virtual model and related automatically generated technical drawing (source: http://www.cad-schroer.com/products/medusa4.html)

In the current education system, creation of technical documentation is the main content of education in this area. The standard teaching process devotes two thirds of the allocated time to technical drawing - theory, drawing on paper, or drawing on a $\mathrm{PC}$ in a CAD system. Only one third of the total allocated time is dedicated to the CAE system and deals with the topic of computer supported design, i.e. to the processes and tools that support the invention and the creativity of the creator or designer (as shown by the results of the analysis of the State Educational Program for Secondary Vocational/Technical Schools [17] performed by the authors).

Up-to-date $\mathrm{CAD} / \mathrm{CAE}$ systems can automatically generate complete technical docu-mentation resulting from a draft/plan and simulated tests of the machine elements or machine function units [18]. This creation of technical documentation is predominantly the subject of teaching, which precedes modelling and simulation methods. In the traditional way of teaching a great part of time (lesson) allocation is devoted to technical drawing - theory, manual drawing on paper or computer assisted drawing in CAD systems. As a consequence then only one third of the total time allocation in the study programs (subject curricula) is devoted to CAD/CAM systems (as results from the analysis of the State Educational Program for upper secondary technical schools show). But on the other hand a survey of labor market requirements showed that the labour market accentuates requirements of the graduates' skills in the modelling and simulation field [19].

One possibility as to how the requirements of technical practice could be reflected in schools (in education) is to increase time allocation for CAD/CAE system teaching. This would result in necessary modification to the relevant school documentation and 
a time-consuming decision-making process in the area of technical education from which the relevant number of lessons would be reallocated to increase the number of lessons needed for CAD/CAE system teaching. The authors of the paper have proposed a new, unconventional method to teach CAD/CAE systems, which on the one hand reflects the current needs of both technical practice and labor market and on the other hand maintains the current range of this field in terms of time allocation. In this unconventional method, students (ISCED 3 level) start immediately with machine element draughts and modelling. In the next stage the students create the necessary technical documentation to the proposed and modelled element. A key question related to this method (teaching methodology) is whether the reduction of technical drawing teaching will have a negative impact on the students' attainment.

\section{Content and methodology of the research}

The most effective way to reflect the requirements of technical practice in education is to increase the time allocation for CAE systems. However, such a procedure would entail a necessary adaptation of school documents and a lengthy process of deciding as to which field of technical education we would take the time from in order to increase the time allocated to $\mathrm{CAD} / \mathrm{CAE}$. That is why we prepared a new, nontraditional procedure for $\mathrm{CAD} / \mathrm{CAE}$ systems teaching which reflects the requirements of practice - increase of the time allocation for modelling and simulation, but with total time for $\mathrm{CAD} / \mathrm{CAE}$ systems remaining the same. In the proposed methodology, students begin with the design and modelling of the components. After that a simulations phase follows and finally, the creation of technical documentation for the proposed 3D model of the component is included. We believe that this proposed innovative approach to $\mathrm{CAD} / \mathrm{CAE}$ system teaching adheres more closely to the practices established in technical practice. Today, the idea or intention of the creator is at first "materialized" in the form of a virtual 3D model, whose behaviour can be simulated by the creator and subsequently modified in the virtual world of CAD/CAE systems. And only at the end is the technical documentation for the production produced (generated). The given situ-ation is most visible in the catalogues of construction companies in which one has the opportunity to choose from the home designs on offer. A customer is given a possibility to go through a virtual 3D home model and to specify to the designer parameters for any modifications. The designer uses the CAD/CAE system to design changes according to customer's requirements and to generate a new virtual 3D model which is once again at the disposal of the customer. This may be repeated several times. Only at the end of the entire design process is the technical documentation developed. As can be seen from this example, production of the technical documentation is also in practice only a secondary activity.

However, the main idea of the proposed methodology is a significant reduction (by half) of the time allocated to teaching the creation of technical documentation. It is natural that such an intervention might negatively affect students' learning achievements. In order to assess the extent to which this intervention will influence the attainment of the students, it is necessary to define the performance standard from the subject area and to establish a methodology for verification of the achieved results. 
Required knowledge and skills related to the area of technical documentation creation were divided as follows.

\section{Theoretical knowledge}

- Knowledge of standards in the field of technical documentation

- Knowledge of the functions and tools of the selected CAD system to create 2D technical documentation

- Theoretical knowledge of the drawing procedures (manual/PC) of the drawing documentation

\section{Practical skills}

- Reading of technical drawings with comprehension

- Creating technical documentation in accordance with the standard - manually

- Creating technical documentation in accordance with the standard - using a CAD system

When preparing new curricula, we want to achieve time savings made at the expense of mastering practical skills, especially when creating technical documentation. As mentioned, the current $\mathrm{CAD} / \mathrm{CAE}$ systems can automatically generate technical drawings from virtual 3D models. Therefore, in this part of teaching we will rather focus on reading comprehension of technical documentation and theoretical knowledge of procedures for technical documentation creation. We further define this knowledge and skills as essential. We assume that students will be able to overcome their handicap of the absence of practical skills in drawing technical drawings through their application practice. At the same time today's developments and trends in the use of $\mathrm{CAD} / \mathrm{CAE}$ systems simply relieve creators of this activity.

By doubling the time allocation for CAE systems, we expect, of course, that student attainment in the area of design and simulation will be improved. Currently, curriculum design for the entire issue of CAD/CAE system teaching at secondary vocational schools is under review (Fig. 10).

In the traditional (standard) way of CAD/CAE system teaching, assessment of students is clearly defined. Students in the first grade are expected to deliver technical drawings made according to given norms. On the basis of the norms and the assessment criteria, which they have to fulfil, they are given a mark from a scale $1-5$, where 1 represents the best possible assessment and 5 unsatisfactory assessment. In the second grade students fulfil an assignment to produce a machine element and its technical drawing using software for technical drawing and model designing. An overview of some selected assignments (examples) for each topic is found in an official text book (Task Collection). The tasks involved in this collection start with simple lines creation and continue with more complicated assignments focused on the use of advanced CA software tools and end in particular with an assignment to process complete technical documentation of a shaft. Through these assignments students learn to use most of the software tools and to understand the logic of the given software. Students are assessed continuously, on the basis of their achievements within the fulfilment of the given assignment and on the basis of the fulfilment of clearly defined conditions of the particular tasks. 


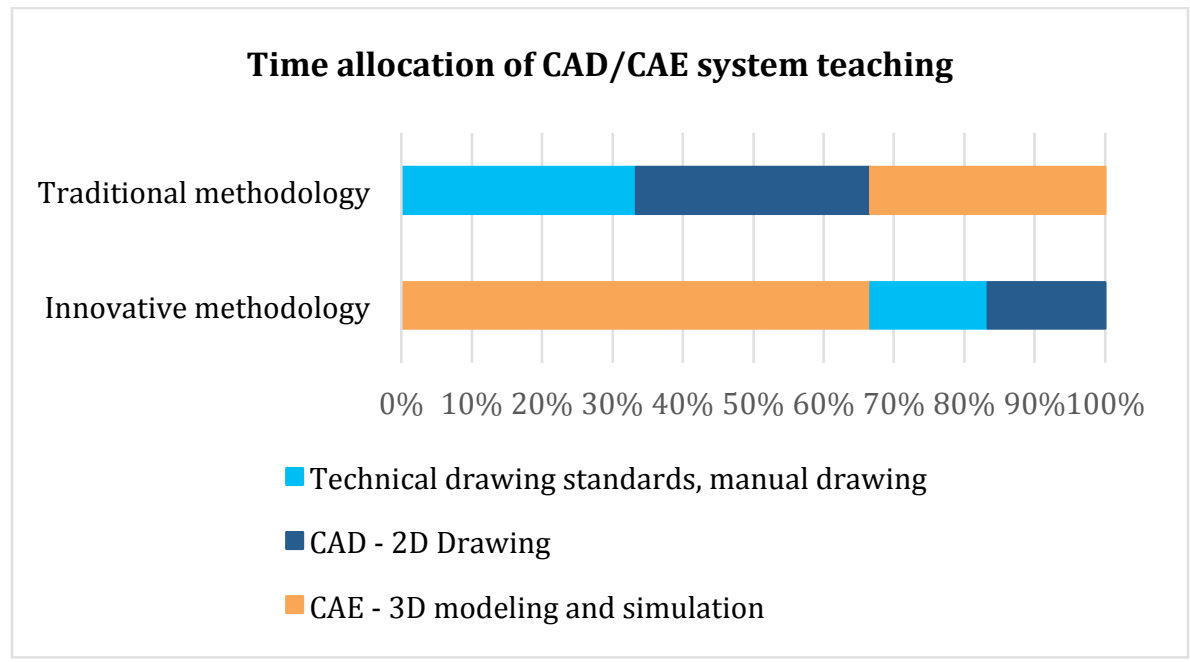

Fig. 10. Time allocation breakdown graph

To find the answer to the research question whether the reduction of the technical drawing teaching will have a negative impact on the students' attainment, we plan to carry out a pedagogical experiment with two groups of students. The experimental group is going to be taught in accordance with the proposed innovative methodology of $\mathrm{CAD} / \mathrm{CAE}$ system teaching and the reference (control) one in accordance with the traditional way of teaching. It means that the experimental group of students is going to have an increased number of lessons focused on modelling and simulation and a decreased number of lessons dealing with training focused on the traditional method of drawing. Both groups will have the same total time allocation for technical drawing and modelling lessons, but the ratio of technical drawing lessons to modelling lessons in the case of the reference (control) group will be 2:1 while in the case of the experimental group it will be $1: 2$. The intended duration of the experiment is two academic years. To create two groups of equivalent research samples of students, relevant secondary technical schools (ISCED 3) will be approached. Assessment of the students of both groups will be done in the same way (the above-mentioned one, used within the traditional methodology of CAD/CAE system teaching). In particular, at the end of the second grade the students of both groups will be given two assignments. The first assignment is going to be a task to model a machine element following a given technical drawing and using a CA program for 3D modelling. The second assignment is going to be a task to model the same machine element from plasticine. Based on the produced machine elements - the models prepared in the CA software and the models made from plasticine - we will evaluate which group of students (whether the experimental or the reference one) will achieve better learning results and will better understand the issue of technical parts design and 3D modelling.

Currently the project of the experiment is in its preparatory phase. The research hypotheses which are going to be tested within the project are the following ones: 
H1: The members of the experimental group will achieve significantly better learning achievements than the members of the control reference group in acquirement of the knowledge and skills in the area of modelling and simulation in CAD/CAE systems.

$\mathrm{H} 2$ : The members of the experimental group will achieve approximately the same learning achievements as the members of the control reference group in acquirement of the knowledge and skills in the key areas of technical documentation creation and reading.

The hypothesis $\mathrm{H} 1$ follows the assumption that a higher time allocation devoted to teaching modelling and simulation in CAD/CAE systems will influence students' learning achievements in a positive way, which is logical and predictable. But the key point of this hypothesis is the fact that this will be achieved despite the decreased time allocation for training devoted to manual creation of technical documentation, i.e. we do not consider these skills (except the basic knowledge) as necessary to developing students' skills in working with CAD/CAE systems. Contrary to the hypothesis H1, the hypothesis $\mathrm{H} 2$ assumes that the decreased number of lessons devoted to teaching technical drawing and creation of technical documentation will not have any significant negative impact on students' knowledge and skills.

\section{Conclusion}

If the proposed experiment confirms the given hypothesis when carried out, it will thus be proved that our above-presented unconventional methodology of teaching CAD/CAE systems at upper-secondary schools better prepares students to meet the requirements of technical practice regarding their knowledge and skills related to modelling and simulation in CAD/CAE systems. Such an untraditional process would have a clear advantage in not imposing any extended material or time requirements. It would be enough to modify the teaching process with a change in time allocation for parts of the education in the given area.

As has been presented, the new methodology of CAD/CAE system teaching is based on a change in the amount of lesson time used for modelling and simulation, and will not affect total time allocation. This means that the time allocation for technical drawing teaching will be reduced and the spare lessons will be given over mainly to 3D modelling. Thereby also some new topics related to modelling and simulation, which up to now because of the limited time allocation could not be incorporated into the school curricula (School Educational Plan), could be included into the teaching. The topics planned to be taught within the new methodology of CAD/CAE system teaching are as follows:

1. System user environment

2. 2D draught creation

3. 3D bodies and technical elements drawing

4. Tin-plate modelling

5. Texturing and setting-out of $3 \mathrm{D}$ bodies and technical elements

6. Simulations through 3D bodies

7. Technical drawing creation 


\section{References}

[1] Ye, X., Peng, W., Chen, Z. and Cai, Y., Today's students, tomorrow's engineers: an industrial perspective on CAD education. Computer-Aided Design, Volume 36, 2004, pp. 14511460 https://doi.org/10.1016/j.cad.2003.11.006

[2] Fořt, P. and Kletečka, J., Autodesk Inventor. Brno, Computer Press, 2004

[3] Vláčilová, H.,Vilímková, M. and Hencl, L., SolidWorks. Brno, Computer Press, 2006

[4] Bilalis, N., Computer Aided Design CAD. INNOREGIO: dissemination of innovation and knowledge management techniques. Technical University of Crete, 2000

[5] Chang, K. H., Product Design Modelling using CAD/CAE. Academic Press USA, 2014

[6] PwC, Prieskum dodávatel'ov automobilového priemyslu/Survey of automotive industry providers, 2014. Available at: https://www.pwc.com/sk/sk/publikacie/assets/2014/pries kum-dodavatelov-automobiloveho-priemyslu-2014.pdf

[7] Belmans, R. and Geysen, W., CAD-CAE in Electrical Machines and Drives Teaching. European Journal of Engineering Education, Volume 13, Issue 2, 1988, pp. 205-212 https://doi.org/10.1080/03043798808939417

[8] Kaminaga, K., Fukuda, Y. and Sato, T., Successful examples in CAD/CAE teaching. Sun, Q., Tang, Z.and Zhang, Y. (Eds.), Computer Applications in Production Engineering. IFIP Advances in Information and Communication Technology, pp. 214-221. Boston, Springer, 1995, https://doi.org/10.1007/978-0-387-34879-7 23

[9] Arthur, P. (Ed.), CAD/CAM in Education and Training. Proceedings of the CAD ED82 Conference. London, Kogan Page Ltd, 1984. https://doi.org/10.1007/978-1-4684-8506-6

[10] Asperl, A., How to teach CAD. Computer-Aided Design and Applications, Volume 2, Issue 1, 2005, pp. 459-468, https://doi.org/10.1080/16864360.2005.10738395

[11] Ru-xiong, L. and Song-hua, J., Teaching Technique Innovation on CAD/CAM/CAE of Mold Course. IERI Procedia 2, 2012, pp. 137-141

[12] Xin-fang, Y. and Ji-feng, L., Probe on the Teaching Innovation of CAD/CAM for Application-oriented Course. Journal of Jiangsu Teachers University of Technology, Volume 10, Issue 2, 2004, pp. 94-96

[13] Wang, H., Research on the Teaching System based on the Characteristics of the Threedimensional CAD/CAM. New Technology \& New Process, Volume 27, Issue 2, 2012, pp. $16-18$

[14] Wittmann, E. C., The Mathematical Training of Teachers from the Point of View of Education. Journal für Mathematik-Didaktik, 10/1989, pp. 291-308

[15] Humenberger, H. and Reichel, H. C., Teaching student teachers: various components of a complex task. Teaching Mathematics and Computer Science, Debrecen, Volume 1, Issue 1, 2003, pp. 55-72 https://doi.org/10.5485/TMCS.2003.0006

[16] Lantada, A. D., Morgado, P. L., Munoz-Guljosa, J. M., Otero, J. E. and Muňoz Sanz, J. L., Comparative study of CAD-CAE programs taking account of the opinions of students and teachers. Computer Applications in Engineering Education, Volume 21, Issue 4, 2010, pp. 641-656, https://doi.org/10.1002/cae.20509

[17] Jakubová, G., Vzdelávacie programy/ Educational programs. Bratislava, ŠIOV, 2013. Available at: http://www9.siov.sk/statne-vzdelavacie-programy/9411s

[18] http://www.uiam.mtf.stuba.sk/predmety/gms/studijne texty/GMS10-09.pdf

[19] Palaj, M. and Skačan, M.,Vyučovanie technických predmetov na stredných školách z pohl'adu začínajúcich učitel'ov / Teaching technical subjects at secondary schools from the point of teacher novices' view. Technika a vzdelávanie / Technology and education, Volume 5, Issue. 2, 2016, pp. 43-45 


\section{$7 \quad$ Authors}

Peter Kuna, Mgr., Ph.D. works as an assistant professor at the Department of Technology and Information Technologies at the Faculty of Education, Constantine the Philosopher University in Nitra. Areas of his research interest are programming industry control systems and educational/training activities for professionals in industrial practice in the automation branch. He co-operates with companies from the manufacturing practice at solving technical problems and acts as a specialty external lecturer for PLC system programmers. He is the author and co-author of 3 monographs and several articles published mainly abroad.

Alena Hašková, Prof., Dr., Ph.D. is a professor of Technology of Education. She works at the Department of Technology and Information Technologies at the Faculty of Education, Constantine the Philosopher University in Nitra. Her primary interests are methodology of technical subject teaching, ICT applications in education, development of educational environments and their use for specific purposes and optimization of school management. She is the author and co-author of 11 monographs, 10 textbooks and more than 270 articles published in Slovakia and abroad.

Miloš Palaj, Mgr. is a graduate of the teacher training study program at the Faculty of Education, Constantine the Philosopher University in Nitra, subject specialization teaching of practical training. Currently he is a Ph.D. student at the Department of Technology and Information Technologies at the same Faculty, study program Didactics of Technical Subjects. The topic of his thesis is Teaching System for Low Cost Control Unit Programming. At the same time he works as a teacher at the Secondary Vocational Polytechnic School in Zlaté Moravce, where he teaches subjects Digital processing, Computer techniques, Applied Informatics, Computer systems and Laboratory measu-rements.

Miloslav Skačan, Mgr. is a graduate of the teacher training study program at the Faculty of Education, Constantine the Philosopher University in Nitra, subject specialization teaching of practical training. Currently he is a Ph.D. student at the Department of Technology and Information Technologies at the same Faculty, study program Didactics of Technical Subjects. The topic of his thesis is Alternative Ways of Teaching CAD/CAE Systems. At the same time he works as a teacher at the Secondary Vocational Polytechnic School in Zlaté Moravce, where he teaches subjects Technical graphics, Computer networks and Computer systems.

Ján Záhorec, Dr., Ph.D. works as an assistant professor at the Department of Didactics of Natural Sciences in Primary Education, Institute of Educational Sciences and Studies, Faculty of Education, Comenius University in Bratislava. The areas of his research are informatics and electronically supported learning. He is interested in deve-loping fully interactive educational environments and e-learning technologies and their applications for specific purposes into the educational process at various levels of the school system. He is the author of more than 83 publications (articles in reviewed journals, proceedings of conferences, chapters in monographs, teaching texts) published in Slovakia and abroad.

Article submitted 29 December 2017. Resubmitted 28 January 2018. Final acceptance 06 February 2018. Final version published as submitted by the authors. 